\title{
A socioeconomic evaluation of early-stage and moderate glaucoma patients
}

Miglè Lindžiūtè, Ingrida Janulevičienè ${ }^{2}$

${ }^{1}$ Faculty of Medicine, Lithuanian University of Health Sciences, Kaunas, Lithuania; ${ }^{2}$ Department of Ophthalmology, Lithuanian University of Health Sciences, Kaunas, Lithuania

\section{Abstract}

Purpose: The aim of this study was to compare costs related to glaucoma treatment for early- and moderate-stage glaucoma patients.

Design: Descriptive observational study.

Methods: The study was conducted at the Eye Clinic in the Hospital of the Lithuanian University of Health Sciences Kauno Klinikos in Lithuania. An original questionnaire was administered to 80 open-angle glaucoma patients. Data regarding the age, gender, living area, occupation, income, concomitant diseases, frequency of outpatient visits, use of topical antiglaucoma and other medications, treatment and transportation costs were collected. The Hodapp classification was used to divide patients into two main groups of early- and moderate-stage glaucoma according to visual field loss. Results with $p<0.05$ were interpreted as statically significant.

Results: There were 37 patients with early-stage glaucoma and 43 patients with moderate glaucoma. Moderate stage glaucoma patients were $73( \pm 8)$ years old, while patients with early-stage glaucoma were $63( \pm 11)$ years old, $(p<0.001)$. Early-stage glaucoma patients visited their ophthalmologist $2.5( \pm 1.5)$ times per year, while patients with moderate glaucoma had $4.4( \pm 2.7)$ outpatient visits per year $(p<0.001)$. Patients with early-stage glaucoma used $1.8( \pm 0.9)$ medications, while patients with moderate glaucoma used $2.9( \pm 0.9)$ medications $(p<0.001)$. Combined costs for treatment and transportation totaled an average of $4.7 \%$ of patient income. Patients that were in the early stages of glaucoma spent about $3.2 \%$ of their annual income for glaucoma care and transportation, while patients with

Correspondence: Miglè Lindžiūtè. P. Luksio street 8 - 25, LT-49355 Kaunas, Lithuania. E-mail: migle.lindziute@gmail.com 
moderate-stage glaucoma spent about $5.9 \%$ of their income $(p=0.003)$. Conclusion: Moderate-stage glaucoma patients had significantly higher expenses related to glaucoma than early-stage glaucoma patients. Costs related to glaucoma comprised a significantly greater part of the income of patients who were retired than patients who were employed.

Keywords: cost evaluation, economic evaluation, glaucoma, glaucoma management, glaucoma treatment costs, socioeconomics

\section{Introduction}

Glaucoma is a neurodegenerative disorder in which degenerating retinal ganglion cells produce significant visual disability. ${ }^{1}$ Despite the fact that the pathogenesis of glaucoma is not completely understood, it is widely accepted that elevated levels of intraocular pressure compress the optic nerve and cause progressive optic neuropathy associated with visual field loss.

Intraocular pressure is determined by the balance between secretion of aqueous humor by the ciliary body and its drainage through two independent pathways: the trabecular meshwork and the uveoscleral outflow pathway. ${ }^{2}$ When aqueous humor outflow is disrupted, intraocular pressure increases. This disruption can occur when the drainage at the trabecular meshwork is blocked (in the case of open-angle glaucoma) or when there is a narrowing of the angle of drainage (in the case of angle-closure glaucoma). Since prolonged periods of elevated intraocular pressure lead to vision loss, glaucoma can result in complete blindness.

Glaucoma is the cause of approximately $12 \%$ of cases of blindness. ${ }^{3}$ About $10-11 \%$ of cases of blindness in Western Europe and USA are caused by glaucoma, and these numbers are increasing. ${ }^{4}$ It is estimated that $3 \%$ of the global population over 40 years of age currently has glaucoma, the majority of whom are undiagnosed. ${ }^{5}$ Projections estimate the prevalence of glaucoma worldwide will rise to 79.6 million by 2020 and counting as the population continues to age. ${ }^{6}$

Since the glaucomatous process is irreversible and glaucoma is often asymptomatic during the early stages, diagnosis and treatment are crucial before the process reaches advanced stages. ${ }^{7-9}$ Therefore, early intervention is essential to slow disease progression. ${ }^{2}$ The main objective of treatment is to preserve the quality of life of the patient by slowing visual loss.

Reduction of intraocular pressure is the only proven method to treat glaucoma. ${ }^{10}$ The target intraocular pressure should be achieved with the minimum amount of medications and fewest possible adverse effects. There are several classes of medications that lower intraocular pressure, including: prostaglandin analogues, $\beta$-adrenergic blockers, $\alpha$-adrenergic antagonists, carbonic anhydrase inhibitors, and cholinergic antagonists. In general, prostaglandin analogues are the first line of 
medical therapy. This drug class reduces intraocular pressure by reducing outflow resistance, resulting in increased aqueous humor flow through the uveoscleral pathway. ${ }^{11}$ However, as the disease progresses, patients usually require more than one medication to lower their intraocular pressure. ${ }^{12}$

Since glaucoma is not curable, patients affected with glaucoma require treatment for the rest of their lives. Lifelong treatment of glaucoma poses a financial challenge to the patient; this affects drug compliance, which plays a major role in treatment outcome. ${ }^{13}$ The fact that patients need more antiglaucoma medications as the disease progresses suggests that the direct costs of glaucoma treatment increase as disease severity worsens. ${ }^{14,15}$ Therefore, patients with moderate and advanced glaucoma have higher economic challenges than the healthy population or patients in the early stages of glaucoma. ${ }^{16}$

The prevalence of glaucoma in Lithuania has been rising in the past decade from a rate of 25.6/1000 in 2011 to $30.6 / 1000$ in $2015 .{ }^{17} \mathrm{~A}$ compulsory health insurance model has been established in Lithuania by the Law on Health Insurance and other laws. This model is based on the principles of universality and provides the possibility of receiving individual healthcare services financed from the Compulsory Health Insurance Funds to insured individuals. ${ }^{18}$ Reimbursable medicines are prescribed to patients in an outpatient setting by primary care physicians or specialists. Most insured patients diagnosed with glaucoma are reimbursed at $80 \%$ of glaucoma medication costs. However, there is insufficient information about the direct costs of glaucoma treatment and care payed for by patients in Lithuania, as the socioeconomic aspects of glaucoma in the country have never been investigated before.

Therefore, the objective of this study was to determine the relation between demographic characteristics, stage of glaucomatous process, and economic challenges of treatment and other costs related to glaucoma.

\section{Methods}

A descriptive observational study was conducted at the Eye Clinic of the Hospital of the Lithuanian University of Health Sciences Kauno Klinikos from June to August 2017. The goal of our study was to find out whether early detection and treatment of glaucoma could significantly reduce the economic burden of this disease.

In order to compare the economic challenges of treatment and other costs related to the stage of glaucoma, the calculated sample size providing $80 \%$ power to detect a standardized difference of 1.5 in treatment cost between early and moderate glaucoma groups was 35 in each group, assuming two-sided tests and a $5 \%$ significance level. An original questionnaire was administered to 80 patients with open-angle glaucoma. There were 37 patients (46.3\%) with early-stage glaucoma and 43 patients $(53.8 \%)$ with moderate glaucoma. 
Inclusion criteria were:

1. patients older than 18 years of age;

2. diagnosed with open-angle glaucoma by a qualified glaucoma specialist at least two years before the questionnaire was administered;

3. actively treated with topical antiglaucoma medications; and

4. willing and able to give consent.

Exclusion criteria were:

1. patients with end-stage glaucoma;

2. patients who underwent surgical or laser glaucoma treatment;

3. advanced age-related macular degeneration, vitreous hemorrhage, diabetic retinopathy, or any progressive retinal or optic nerve disease other than glaucoma; and

4. refusal to give informed consent.

Informed consent was obtained from all participants before they participated in the study. The study was conducted in accordance with the Declaration of Helsinki and approved by our institutional Research Ethics Committee - Lithuanian University of Health Sciences Centre for Bioethics.

The questionnaire was composed of a set of 28 questions. Collected data included:

1. age and gender;

2. occupation and income;

3. frequency of outpatient visits;

4. living area, means, cost, and duration of transportation;

5. concomitant diseases;

6. use and costs of topical antiglaucoma medications; and

7. use of systemic medications.

Data about costs of replacing glasses, loss of wellbeing, rehabilitation, nursing, and other indirect costs such as lost earnings and productivity were not included. Costs related to glaucoma screening were not included in the evaluation of treatment costs since these services are fully compensated by the Compulsory Health Insurance Fund.

The patients were divided into two main groups of early-stage and moderate-stage glaucoma using the Hodapp-Parrish-Anderson classification, ${ }^{19}$ which is based on visual field assessment. Typically, the visual field is assessed by standard automated perimetry, in which patients respond to light dots presented at fixed locations in the field of vision by a perimeter that determines a sensitivity threshold for each location. ${ }^{20}$

Glaucomatous loss was defined as:

- mean deviation (MD) <-6 dB;

- fewer than 18 points depressed below the 5\% probability level and fewer than 10 points below the $p<1 \%$ level; and

- no point in the central $5^{\circ}$ with a sensitivity of less than $15 \mathrm{~dB}$. 
Moderate glaucomatous loss was defined as:

- $\mathrm{MD}<-12 \mathrm{~dB}$;

- fewer than 37 points depressed below the 5\% probability level and fewer than 20 points below the $p<1 \%$ level;

- no absolute deficit $(0 \mathrm{~dB})$ in the central $5^{\circ}$; and

- only one hemifield with sensitivity of $<15 \mathrm{~dB}$ in the central $5^{\circ}$.

Patients with advanced glaucomatous loss were not included in this study.

Statistical analysis was performed using a software package SPSS v. 17.0 (IBM Corp., Armonk, NY, USA). Independent samples Student's t-tests were used to compare and determine the equality of means in two populations. The one-way analysis of variance (ANOVA) was used to determine whether there are any statistically significant differences between the means of three or more independent groups. The Mann-Whitney $\mathrm{U}$ test was used to compare the differences between two independent groups, while the dependent variable was ordinal. The Chi-square test of independence was used to analyze differences in two groups when the dependent variable was measured at a nominal level. Pearson correlation coefficient was used to measure the linear correlation between two variables. Cramer's $V$ coefficient factor was used to measure the association between two nominal variables. Results with a significance level of $p<0.05$ were interpreted as statistically significant.

\section{Results}

Eighty open-angle glaucoma patients participated in the study. Demographic characteristics, rates of comorbidity, and types of medications used to treat glaucoma are shown in Table 1. The average age of male subjects was $66.8( \pm 10.6)$ years and the average age of female subjects was $69.2( \pm 11.1)$ years, $p=0.343$. There was no significant difference between the average age of males and females.

Patients were diagnosed with glaucoma for an average of $9.2( \pm 7.3)$ years (minimum of 2 years; maximum of 30 years). Participants visited their ophthalmologist on average about $3.3( \pm 1.7$ ) times per year (minimum 1 , maximum 7 ).

There was no significant correlation between the amount of outpatient visits per year and the age of patients $(r=0.002 ; p=0.985)$ and distance needed to travel to the hospital $(r=0.129 ; p=0.254)$. Employed patients had an average of $3.5( \pm 2.3)$ visits per year, while retired patients had $3.6( \pm 2.6)$ visits per year, showing that there was no significant relationship between employment status and number of outpatient visits per year, $\mathrm{p}=0.833$. However, from the 31 employed glaucoma patients, 21 $(67.7 \%)$ had to take a day off to visit their ophthalmologist.

Patient income was distributed in the groups up to $€ 300$ and from $€ 300$ to 500, while only less than a fifth of patients had an income above $€ 500$ (Fig. 1).

On average, patients lived $51( \pm 66) \mathrm{km}$ (minimum $1 \mathrm{~km}$; maximum $260 \mathrm{~km}$ ) away from the hospital. Most patients came to the hospital by private car or public trans- 
Table 1. Demographic characteristics, concomitant diseases, and types of medications used to treat glaucoma of patients included in the study

\begin{tabular}{|l|l|}
\hline & All patients \\
\hline Age, mean $\mathbf{\text { SD}}$, years & $68.3 \pm 10.9$ \\
\hline Sex, N (\%) & \\
\hline Male & $30(37.5)$ \\
\hline Female & $50(62.5)$ \\
\hline Employment status, $\mathbf{N}(\%)$ & \\
\hline Employed & $31(38.8)$ \\
\hline Retired & $49(61.2)$ \\
\hline Rates of comorbidity, $\mathbf{N}(\%)$ & \\
\hline Cataracts & $27(33.8)$ \\
\hline Arterial hypertension & $46(57.5)$ \\
\hline Type 2 diabetes & $10(12.5)$ \\
\hline Circulatory system conditions & $5(6.3)$ \\
\hline Asthma & $5(6.3)$ \\
\hline Type of medications used, $\mathbf{N}(\%)$ & \\
\hline$\beta$-adrenergic blockers & $54(67.5)$ \\
\hline Carbonic anhydrase inhibitors & $51(63.8)$ \\
\hline$\alpha$-adrenergic antagonists & $26(32.5)$ \\
\hline Prostaglandin analogs & $58(72.6)$ \\
\hline
\end{tabular}

\section{Patient distribution by income}

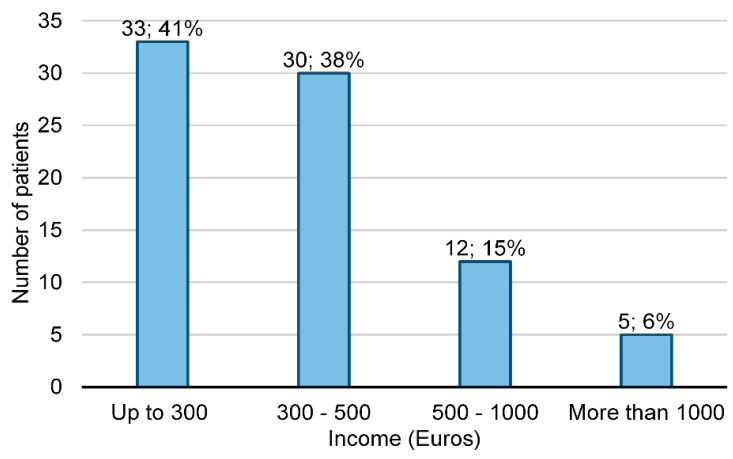

Fig. 1. Distribution of patients in different income groups. The income of most patients was up to $€ 300$ and between $€ 300$ and 500 , while only less than a fifth of patients had an income above $€ 500$. 


\section{Choice of transport and distance by mean of transport}

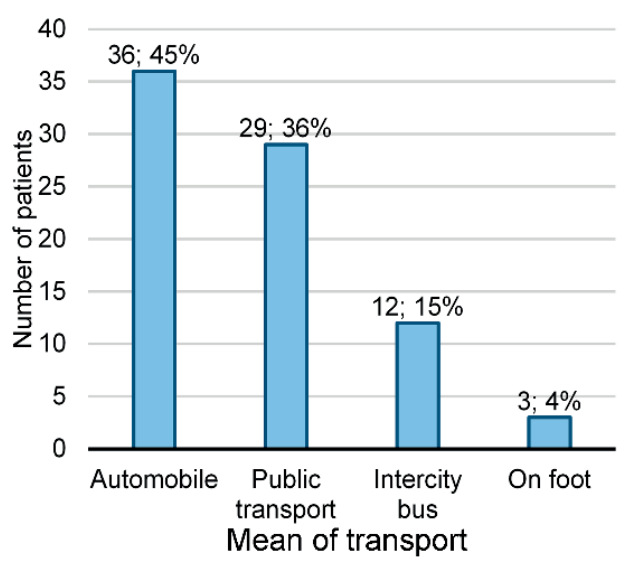

(a)

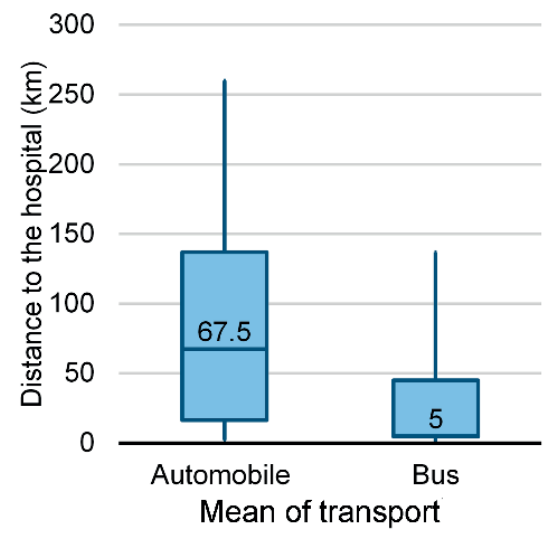

(b)

Fig. 2. Chosen means of transport and variation of distance by mean of transport. (a) Distribution of chosen transport means used to arrive to the hospital. (b) Box-plot showing the average distance needed to travel to the hospital by different means of transport.

portation, and some using an intercity bus or on foot (Fig. 2a). Patients who came by automobile lived statistically significantly further away than the ones that came to the hospital by bus, $p<0.001$ (Fig. 2b). Twenty-four (30\%) patients drove themselves to outpatient visits and $12(15 \%)$ were taken to the hospital by a family member or friend. The average time it took for participants to get to the hospital was 1 hour, first quartile was up to 20 minutes, the median was 30 minutes, and the third quartile was 1.5 hours.

Sixty-one $(76.3 \%)$ patients visited the ophthalmologist by themselves, while the other $19(23.8 \%)$ patients came to the hospital with an accompanying person. Seventeen $(89 \%)$ of them accompanied the patient because of their inability to travel or get to the hospital alone. Twelve (63\%) of the 19 accompanying persons were employed and $6(50 \%)$ of them had to take time off to take the patients to the hospital.

The average cost of travel for one visit to the ophthalmologist was $€ 10.84$ ( \pm 12.94) (minimum $€ 0$, maximum $€ 48$ ). Participants that came to the outpatient visits by bus had an average travel cost of $€ 4.69$ ( \pm 5.90$)$, while patients who came to the hospital by car payed statistically significantly more, approximately $€ 18.72( \pm 14.84)$ per visit, $p<0.001$ (Fig. 3a). Patients who chose to travel to the hospital by bus lived an average of $27( \pm 36) \mathrm{km}$ to the hospital, while patients who lived further away from the hospital, approximately $83( \pm 80) \mathrm{km}$, chose to take an automobile, $p<0.001$. The result of correlation analyses shows that there was a statistically significant rela- 
Transport cost by mean of transport and relation between travel distance and cost

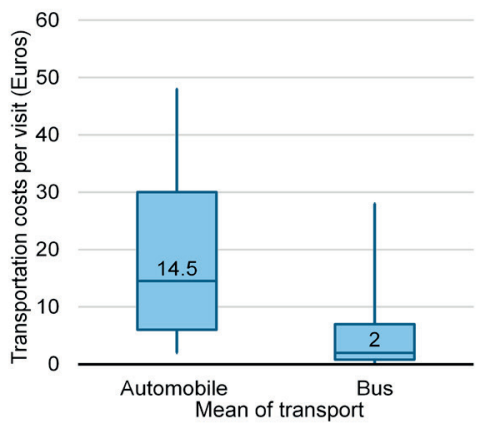

(a)

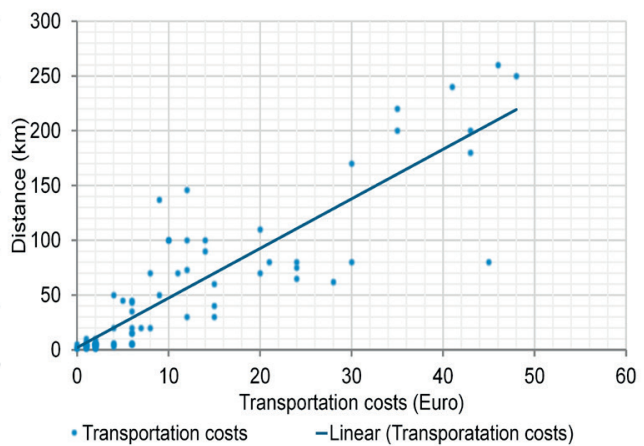

(b)

Fig. 3. Transport cost by means of transport and relation between travel distance and cost. (a) The variation of transport costs per one visit by chosen means of transport. (b) Correlation analyses shows that there was a statistically significant relationship between the distance the patient travels to the hospital and travel cost. The scattering of variables and linear regression is shown.

tionship between the distance traveled by patients to the hospital and travel costs, $r=0.879, p<0.001$ (Fig. 3b).

All the patients who participated in this study were divided into two groups using the Hodapp-Parrish-Anderson classification. There were 37 patients (46.3\%) with early-stage glaucoma and 43 patients (53.8\%) with moderate glaucoma. Comparison of demographic characteristics between patients with early- and moderate-stage glaucoma outlines that patients with moderate glaucoma were significantly older and more of them were retired than early-stage glaucoma patients. The distribution by sex was not significantly different in these groups, as shown in Table 2.

A summary of distribution of concomitant diseases and conditions in the early and moderate glaucoma groups is shown in Table 3 . There were significantly more cases of cataracts in the moderate-stage glaucoma group. There was no significant difference of prevalence of diabetes, arterial hypertension, circulatory system conditions, and asthma between patients with early- and moderate-stage glaucoma.

Participants with early-stage glaucoma had been diagnosed in average for 6.6 $( \pm 5.3)$ years, while patients with moderate glaucoma had the disease for a longer time period, approximately $11.2( \pm 8.3)$ years, $p=0.004$. Patients in the early stages of glaucoma visited their eye doctor about $2.5( \pm 1.5)$ times per year, while patients with moderate glaucoma had statistically significantly more visits per year, approximately $4.4( \pm 2.7)$ visits per year, $p<0.001$. Types of medication used and frequency in use of specific types of antiglaucoma medications are detailed in Table 4. 
Table 2. Demographic characeristics of patients with early-stage and moderate glaucoma

\begin{tabular}{|c|c|c|c|c|c|}
\hline & $\begin{array}{l}\text { Early-stage } \\
\text { glaucoma } \\
\text { group }\end{array}$ & $\begin{array}{l}\text { Moderate- } \\
\text { stage } \\
\text { glaucoma } \\
\text { group }\end{array}$ & $x^{2}$ & $\begin{array}{l}\text { Cramer's V } \\
\text { coefficient }\end{array}$ & $p$-value \\
\hline Age, mean $\pm S D$, years & $62.7 \pm 11.2$ & $73.1 \pm 8.0$ & & & $<0.001$ \\
\hline Sex, N (\%) & & & \multirow{3}{*}{0.75} & \multirow{3}{*}{$r=0.097$} & \multirow{3}{*}{0.385} \\
\hline Male & $12(15.0)$ & $18(22.5)$ & & & \\
\hline Female & $25(31.3)$ & $25(31.3)$ & & & \\
\hline Employment status, $\mathrm{N}$ & & & \multirow{3}{*}{19.78} & \multirow{3}{*}{$r=0.497$} & \multirow{3}{*}{$<0.001$} \\
\hline Employed & $24(30.0)$ & $7(8.8)$ & & & \\
\hline Retired & $13(16.3)$ & $36(45.0)$ & & & \\
\hline
\end{tabular}

Table 3. Concomitant diseases, conditions of patients that suffer from early and moderate stage glaucoma.

\begin{tabular}{|l|l|l|l|l|}
\hline & $\begin{array}{l}\text { Early-stage } \\
\text { glaucoma } \\
\text { group, N (\%) }\end{array}$ & $\begin{array}{l}\text { Moderate- } \\
\text { stage } \\
\text { glaucoma } \\
\text { group, } \mathbf{N}(\%)\end{array}$ & $\begin{array}{l}\text { Cramer's V } \\
\text { coefficient }\end{array}$ & p-value \\
\hline Cataracts & $5(13.5)$ & $22(51.2)$ & $\mathrm{r}=0.397$ & $<0.001$ \\
\hline $\begin{array}{l}\text { Arterial } \\
\text { hypertension }\end{array}$ & $18(48.6)$ & $28(65.1)$ & $\mathrm{r}=0.166$ & 0.175 \\
\hline Type 2 diabetes & $4(10.8)$ & $6(13.9)$ & $\mathrm{r}=0.136$ & 0.745 \\
\hline $\begin{array}{l}\text { Circulatory } \\
\text { system } \\
\text { problems }\end{array}$ & $3(8.0)$ & $2(4.7)$ & $\mathrm{r}=0.071$ & 0.658 \\
\hline Asthma & $1(2.7)$ & $4(9.3)$ & $\mathrm{r}=0.136$ & 0.366 \\
\hline
\end{tabular}


Table 4. Frequency in use of different type antiglaucoma medications in early-stage and advanced glaucoma management

\begin{tabular}{|c|l|l|l|}
\hline & $\begin{array}{l}\text { Early-stage } \\
\text { glaucoma group, } \\
\mathbf{N}(\%)\end{array}$ & $\begin{array}{l}\text { Moderate-stage } \\
\text { glaucoma group, } \\
\mathbf{N}(\%)\end{array}$ & All patients, N (\%) \\
\hline $\begin{array}{l}\boldsymbol{\beta} \text {-adrenergic } \\
\text { blockers }\end{array}$ & $22(59.5)$ & $32(74.4)$ & $54(67.5)$ \\
\hline Timolol & $22(59.5)$ & $30(69.8)$ & $52(65.0)$ \\
\hline Betaxolol & $0(0.0)$ & $2(4.7)$ & $2(2.5)$ \\
\hline $\begin{array}{l}\text { Carbonic } \\
\text { anhydrase } \\
\text { inhibitors }\end{array}$ & $17(45.9)$ & $34(79.1)$ & $51(63.8)$ \\
\hline Brinzolamide & $12(32.4)$ & $21(48.8)$ & $33(41.3)$ \\
\hline Dorzolamide & $5(13.5)$ & $13(30.2)$ & $18(22.5)$ \\
\hline $\begin{array}{l}\boldsymbol{\alpha} \text {-adrenergic } \\
\text { antagonists }\end{array}$ & & & $26(32.5)$ \\
\hline Brimonidine & $4(10.8)$ & $22(51.2)$ & $58(72.6)$ \\
\hline $\begin{array}{l}\text { Prostaglandin } \\
\text { analogs }\end{array}$ & $23(62.2)$ & $35(81.4)$ & $23(28.8)$ \\
\hline Latanoprost & $6(16.2)$ & $17(39.5)$ & $16(20.0)$ \\
\hline Brimatoprost & $6(16.2)$ & $8(18.6)$ & $15(18.8)$ \\
\hline Travoprost & $8(21.6)$ & $9(20.9)$ & $4(5.0)$ \\
\hline Tafluprost & $3(8.1)$ & $1(2.3)$ & \\
\hline
\end{tabular}

The distribution of patients by the amount of medications used ranged from one to four topical antiglaucoma drugs (Fig. 4a). Patients with early-stage glaucoma used $1.8( \pm 0.9)$ medications on average, while patients with moderate-stage glaucoma used significantly more drugs, $2.9( \pm 0.9), p<0.001$. The results show a statistically significant difference in direct treatment costs depending on the amount of medications used, $p<0.001$ (Fig. 4b).

The average yearly cost of antiglaucoma medications was $€ 249.75$ ( \pm 109.66$)$ per patient (minimum $€ 36.75$, maximum $€ 463.44$ ). Patients with early-stage glaucoma used medications worth $€ 196.62$ ( \pm 105.12), while patients with moderate stage glaucoma had medication costs of $€ 295.47$ ( \pm 92.31) per year, $p<0.001$ (Fig. 5). Patient costs for topical antiglaucoma medications were reimbursed at $80 \%$ by the Compulsory Health Insurance Fund of the Republic of Lithuania. The average direct cost for annual medication was $€ 107.09$ ( \pm 56.29) (minimum $€ 14.40$, maximum $€ 264)$. 


\section{Variation in treatment cost by amount of medications used}

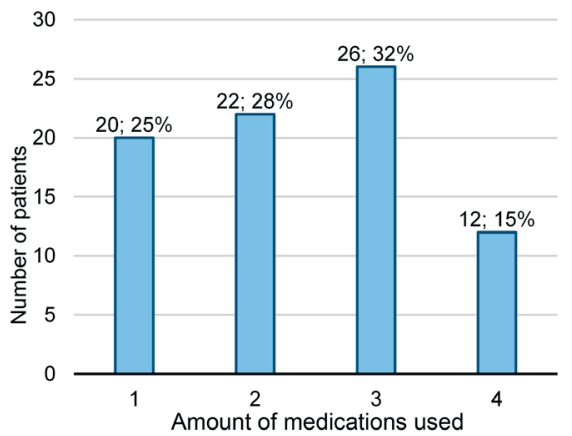

(a)

\section{0}

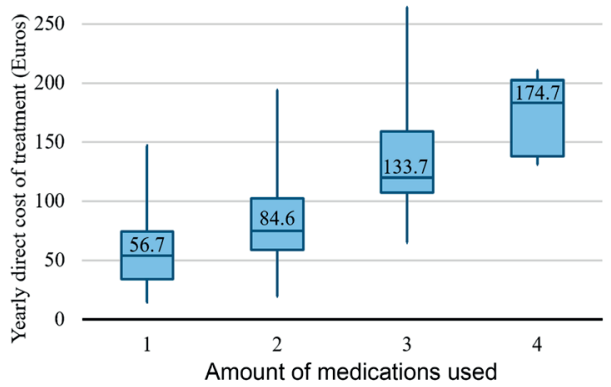

(b)

Fig. 4. Patient distribution by the amount of glaucoma medications used and variation of yearly treatment cost by amount of glaucoma medications used. (a) Patient distribution by the amount of glaucoma medications used. (b) Box-plot showing the variation of yearly cost of treatment by the amount of glaucoma medications used. Results show a significant increase of costs depending on the amount of medications used.

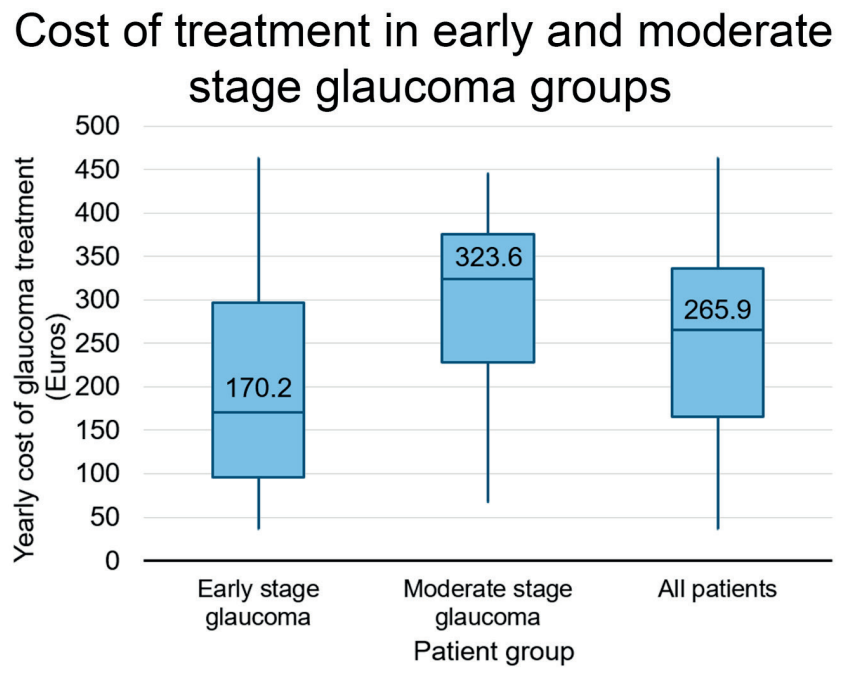

Fig. 5. Variation of yearly treatment cost in early and advanced glaucoma groups. Box-plot showing the variation of yearly cost of treatment in the early-stage and moderate glaucoma groups. 
Combined direct patient treatment and travel costs were about $€ 143.29( \pm 86.61)$ per year on average (minimum $€$ 86.61; maximum $€ 528$ ). Travel costs accounted for about $21 \%$ of combined patient costs. Combined costs for treatment and transportation made up about $4.7 \%$ of patient income. Patients that were in the early stages of glaucoma spent about 3.2\% of their income on costs related to transport and treatment, while patients with moderate-stage glaucoma spent an average of $5.9 \%$ of their income, $p=0.003$. Employed patients spent about $2.7 \%$ of their income for direct glaucoma costs, while retired participants spent a significantly higher amount, $5.9 \%$ of their earnings, $p=0.001$.

\section{Discussion}

The number of people coming to hospital eye departments is likely to increase in the future as a result of an ageing population, increased optometric case findings, and raised public awareness. ${ }^{21}$ This study concludes that patients with moderate-stage glaucoma were significantly older than patients with early-stage glaucoma. This and data from other studies suggest that older age increases the risk of glaucoma progression. ${ }^{22}$

Patients with moderate-stage glaucoma had a higher number of yearly ophthalmologist visits and had glaucoma for a significantly longer time. This shows that patients who suffer from glaucoma longer have a higher progression rate of the disease. Participants of this study who had a moderate glaucomatous process tended to need more medication to reach their target intraocular pressure, which amounts to higher treatment costs.

Many other studies that have researched the economic burden of glaucoma concluded that, as disease severity worsens, resource utilization and direct medical treatment costs increase. This increase in costs was observed in a study done in Europe, which concluded that direct treatment costs increased by $€ 86$ by each incremental step (from $€ 455$ in stage 1 to $€ 969$ in stage 4). ${ }^{15}$ A study conducted in the USA showed a similar outcome, finding that treatment costs amounted to US\$623 in early-stage glaucoma, US\$ 1915 in advanced glaucoma, and US\$ 2511 in end-stage glaucoma. ${ }^{23}$ Likewise, as seen in literature reviews, it appears that several other studies have come to the same result, namely, that increased disease severity is associated with increased costs. ${ }^{24}$ This concludes that older patients with moderate and advanced glaucoma are facing a much higher economic burden than younger patients with early-stage glaucoma.

Glaucoma management strategies aimed at slowing or stopping disease progression, if effective, would be expected to significantly reduce the economic burden of this chronic disease over many years. ${ }^{15}$ Early disease recognition, proactive management, and prevention of progression beyond the early stages may reduce the overall national and personal economic burden, limit the reduction of 
productivity from vision loss, and preserve quality of life. ${ }^{5,15,25}$ Home tonometers would transfer a considerable portion of IOP follow-up to patients themselves, similar to measuring blood sugar and blood pressure at home. The time of medical professionals would be freed to other patients who could benefit more from their care. $^{26}$

Findings about costs related to glaucoma treatment might vary in different countries and studies, but an objective way to observe the differences in glaucoma costs is comparing costs to patient income. In a study conducted in Sweden, the mean annual cost for glaucoma treatment and care was $€ 476 .{ }^{27}$ Other studies undertaken in France and Sweden show that patients spent an average of $€ 390$ and $€ 531$, respectively. ${ }^{28}$ According to data published by the Organization for Economic Co-operation and Development, the average yearly wage is $€ 41,835$ (SEK 399,988) in Sweden and $€ 36,809$ in France. ${ }^{29}$ From this data, we can see that glaucoma patients in Sweden spend about $1.1-1.3 \%$ of their income on costs related to glaucoma, while patients in France spend about $1 \%$ of their income.

In our study, patients spent an average of $€ 143$ annually for glaucoma medications and transport costs combined. The average net monthly earning in Lithuania in 2016 was $€ 602.30$ (yearly income of $€ 7227.60$ ). ${ }^{30}$ Working patients spent about $2.7 \%$ of their income on glaucoma treatment and transportation. The average monthly state social insurance pension in 2015 was $€ 244.50$ (yearly income of $€ 2934$ ). ${ }^{31}$ Since more patients in the moderate-stage glaucoma group were retired and their income came from social insurance pensions, they spent a greater amount of their monthly pay, approximately $5.9 \%$, for glaucoma care. It is evident that glaucoma poses a higher economic burden on this social group.

In our study, direct costs for medication comprised $79 \%$ of combined costs. In a study conducted in Europe, medication costs represent a minimum of $42 \%$ of total direct cost at any disease stage. ${ }^{15}$ Drug costs in Denmark accounted for $57 \%$ of total glaucoma care costs. ${ }^{32}$

Groups of patients for which glaucoma pose a higher economic burden might prefer choosing cheaper alternative antiglaucoma medications with different substance concentrations or might display low treatment compliance due to sparing medication to lower treatment costs. The proportion of patients who deviate from their prescribed medication regimen ranged from $5-80 \% .{ }^{33}$ Low treatment compliance can cause an increase in intraocular pressure and speed up the rate of glaucoma progression. Treatment compliance is fundamental to reduce glaucoma progression; even a small $(1 \mathrm{mmHg})$ reduction in intraocular pressure could reduce glaucoma progression significantly by approximately $10 \% .{ }^{34}$

Even though average travel costs per visit were about $€ 10.84$ ( \pm 12.94$)$, they accounted for $21 \%$ of direct costs. There were similar results in a study published about travel costs for glaucoma patients in London hospitals; travel accounted for approximately one-fifth of total patient costs. ${ }^{21}$ It appears that patients who lived further away had higher transportation costs and would choose travel by automobile 
more often. This problem may occur due to a lack of glaucoma specialists in their counties.

Our study had several limitations. Costs for office visits, glaucoma examinations, replacing glasses, rehabilitation, nursing, and other indirect costs were not included. Information about lost income during visits and lost productivity was not included, and additional costs incurred by accompanying persons were also not included. We assumed that patients were compliant with treatment and did not measure compliance directly by any objective methods.

\section{Conclusion}

Glaucoma is a neurodegenerative disorder in which elevated intraocular pressure causes irreversible damage to the retinal ganglion cells. Lifelong treatment is needed to slow disease progression, and as glaucomatous damage progresses, patients require more medications. Moderate-stage glaucoma patients were older, had glaucoma for longer, had more outpatient visits, and used more medications than early-stage glaucoma patients. Costs related to glaucoma comprised a considerable amount of patient income. However, some groups of patients were more affected than others. Our research shows that moderate-stage glaucoma patients had significantly higher expenses related to glaucoma than early-stage glaucoma patients. Likewise, costs related to glaucoma comprised a much higher portion of income for patients who were retired versus those who were employed. Given that retired patients had a lower income and higher glaucoma costs while also having moderate glaucoma more frequently due to disease duration made them a more socially vulnerable group. This shows that early detection and treatment of glaucoma can significantly reduce the economic burden of this disease.

\section{References}

1. Cohen LP, Pasquale LR. Clinical characteristics and current treatment of glaucoma. Cold Spring Harb Perspect Med. 2014;4(6):a017236. Available from: http://www.ncbi.nlm.nih.gov/pmc/articles/ PMC4031956/

2. Weinreb R, Aung T, Medeiros F. The pathophysiology and treatment of glaucoma. JAMA. 2014;311(18):1901. doi:10.1001/jama.2014.3192

3. Foster A, Resnikoff S. The impact of Vision 2020 on global blindness. Eye (Lond). 2005;19(10):11331135. doi:10.1038/sj.eye.6701973

4. Bourne RRA, Jonas JB, Flaxman SR, et al. Prevalence and causes of vision loss in high-income countries and in Eastern and Central Europe: 1990-2010. Br J Ophthalmol. 2014;12;98(5):629 LP-638. Available from: http://bjo.bmj.com/content/98/5/629.abstract

5. Varma R, Lee PP, Goldberg I, Kotak S. an assessment of the health and economic burdens of glaucoma. Am J Ophthalmol. 2011;152(4):515-522. Available from: http://www.ncbi.nlm.nih.gov/ pmc/articles/PMC3206636/ 
6. Quigley HA, Broman AT. The number of people with glaucoma worldwide in 2010 and 2020. Br J Ophthalmol. 2006;90(3):262-7. Available from: http://www.ncbi.nlm.nih.gov/pmc/articles/PMC1856963/

7. Leite MT, Sakata LM, Medeiros FA. Managing glaucoma in developing countries. Arq Bras Oftalmol. 2011;74(2):83-84. Available from: http://www.ncbi.nlm.nih.gov/pmc/articles/PMC3787827/

8. Bettin P, Di Matteo F. Glaucoma: present challenges and future trends. Ophthalmic Res. 2013;50(4):197-208. Available from: http://www.karger.com/DOI/10.1159/000348736

9. Buys YM, Gaspo R, Kwok K. Referral source, symptoms, and severity at diagnosis of ocular hypertension or open-angle glaucoma in various practices. Can J Ophthalmol. 2017;47(3):217-222. doi:10.1016/j.jcjo.2012.03.031

10. Boland MV, Ervin AM, Friedman DS, et al. Comparative effectiveness of treatments for open-angle glaucoma: a systematic review for the US Preventive Services Task Force. Ann Intern Med. 2013;158(4):271-279.

11. Stewart WC, Konstas AG, Nelson LA, Kruft B. Meta-analysis of 24-hour intraocular pressure studies evaluating the efficacy of glaucoma medicines. Ophthalmology. 2008;115(7):1117e1-1122e1

12. Waldock A, Snape J, Graham C. Effects of glaucoma medications on the cardiorespiratory and intraocular pressure status of newly diagnosed glaucoma patients. Br J Ophthalmol. 2000;84(7):710-713. Available from: http://www.ncbi.nlm.nih.gov/pmc/articles/PMC1723530/

13. Kumbar SK, Mirje M, Moharir G, Bharatha A. Cost analysis of commonly used combination of drugs in primary open angle glaucoma. J Clin Diagn Res. 2015;9(5):FC05-FC08. Available from: http://www. ncbi.nlm.nih.gov/pmc/articles/PMC4484082/

14. Lorenz K, Wolfram C, Breitscheidel L, Shlaen M, Verboven Y, Pfeiffer N. Direct cost and predictive factors for treatment in patients with ocular hypertension or early, moderate and advanced primary open-angle glaucoma: the CoGIS study in Germany. Graefe's Arch Clin Exp Ophthalmol. 2013;251(8):2019-2028. doi:10.1007/s00417-013-2354-z

15. Traverso CE, Walt JG, Kelly SP, et al. Direct costs of glaucoma and severity of the disease: a multinational long term study of resource utilisation in Europe. Br J Ophthalmol. 2005 89(10):1245-1249. Available from: http://www.ncbi.nlm.nih.gov/pmc/articles/PMC1772870/

16. Goldberg I. Stepping up glaucoma management: when and how? Open Ophthalmol J. 2009;3:67-69. Available from: http://www.ncbi.nlm.nih.gov/pmc/articles/PMC2760861/

17. Gaidelytė R, Garbuvienè M, Madeikytė N. Lithuanian Ministry of Health Health Information Centre of Institute of Hygiene Health Statistics of Lithuania 2015; Available from: www.hi.lt

18. National Health Insurance Fund under The Ministry of Health. Healthcare in Lithuania. Vlk.lt. http:// www.vlk.It/sites/en/healthcare-in-lithuania/. Published 2019

19. Susanna R Jr, Vessani RM. Staging glaucoma patient: why and how?. Open Ophthalmol J. 2009;3:5964. 2009. doi:10.2174/1874364100903020059

20. Elze T, Pasquale LR, Shen LQ, Chen TC, Wiggs JL, Bex PJ. Patterns of functional vision loss in glaucoma determined with archetypal analysis. J R Soc Interface. 2014;12(103):20141118-20141118. doi:10.1098/rsif.2014.1118

21. Sharma A, Jofre-Bonet M, Panca M, Lawrenson JG, Murdoch I. Hospital-based glaucoma clinics: what are the costs to patients. Eye. 2010;24(6):999-1005. doi:10.1038/eye.2009.284

22. Heijl A. Concept and importance of visual field measurements to detect glaucoma progression. Glaucoma now. 2010;(2):2-4.

23. Lee PP, Walt JG, Doyle JJ, et al. A multicenter, retrospective pilot study of resource use and costs associated with severity of disease in glaucoma. Arch Ophthalmol. 2006;124(1):12-19. doi:10.1001/ archopht.124.1.12

24. Schmier JK, Halpern MT JM. The economic implications of glaucoma: A literature review. Pharmacoeconomics. 2007;(25):287-308.

25. Vaahtoranta-Lehtonen $\mathrm{H}$, Tuulonen A, Aronen $\mathrm{P}$ et al. Cost effectiveness and cost utility of organized screening programme for glaucoma. Acta Ophthalmol Scand. 2007;(85):508-518.

26. Tuulonen A. Challenges of glaucoma care - high volume, high quality, low cost. Acta Ophthalmol. 2013;91(1):3-5. doi:10.1111/aos.12088 
27. Hagman J. Comparison of resource utilization in the treatment of open-angle glaucoma between two cities in Finland: is more better? Acta Ophthalmol. 2013;91(thesis3):1-47. doi:10.1111/aos.12141

28. Lindblom B, Nordmann J-P, Sellem E, et al. A multicentre, retrospective study of resource utilization and costs associated with glaucoma management in France and Sweden. Acta Ophthalmol Scand. 2005;84(1):74-83. doi:10.1111/j.1600-0420.2005.00560.x

29. OECD Statistics. Stats.oecd.org. 2017 [Internet]. Available from: https://stats.oecd.org/

30. Statistics Lithuania. Labour Market Yearbook 2016. Average net monthly earnings, 2006-2016. Vilnius, Lithuania; 2017. Available from: https://osp.stat.gov.It/services-portlet/pub-edition-file?id=27544

31. Statistics Lithuania. Social Protection in Lithuania 2015. Average monthly state social insurance pension, 2010-2015. Lithuania, Vilnius; 2016. Available from: https://osp.stat.gov.lt/statistikos-leidiniu-katalogas?publication=25060

32. Olsen J, Berdeaux G, Skov J. Glaucoma costs in Denmark in treatment naive patients. Acta Ophthalmol. 2013;91(1):25-31. doi:10.1111/j.1755-3768.2011.02212.x

33. Olthoff C M, Schouten J S, van de Borne B W, Webers C A. Noncompliance with ocular hypotensive treatment in patients with glaucoma or ocular hypertension: an evidence-based review. Ophthalmology 2004;112(6): 953-961

34. Luca Rossetti OSP. Treatment strategies to help prevent Progression. Glaucoma now. 2010;(2):8-9. 


\section{Appendix}

\section{Questionaire:}

1. Gender:
$\square \quad$ Male
$\square \quad$ Female

2. Address:

3. Age:

4. Education:

$\begin{array}{ll}\square & \text { High school graduate } \\ \square & \text { Vocational school } \\ \square & \text { College } \\ \square & \text { University } \\ \square & \text { Other: }\end{array}$

5. Occupation:

$\begin{array}{ll}\square & \text { Employed } \\ \square & \text { Unemployed } \\ \square & \text { Student } \\ \square & \text { Retired } \\ \square & \text { Other: }\end{array}$

6. What is your monthly income?

7. How long have you been diagnosed with glaucoma?

8. How many times a year do you visit your glaucoma specialist for a follow-up?

9. Do you have any eye diseases other than glaucoma? (If yes, which ones?) 
10. Do you have any other medical conditions?

$\square \quad$ Hypertension

$\square \quad$ Type 2 diabetes

$\square \quad$ Asthma

$\square \quad$ Other:

11. Have you undergone any glaucoma surgery?

$\square \quad$ Yes

$\square \quad$ No

12. Have you undergone any other type of eye surgery?

$\square \quad$ Yes

$\square \quad$ No

13. What antiglaucoma medications do you use?

\begin{tabular}{|l|l|l|}
\hline Medication & Total cost & Cost after reimbursement \\
\hline & & \\
\hline & & \\
\hline & & \\
\hline & & \\
\hline
\end{tabular}

14. What systemic medications do you use?

\begin{tabular}{|l|l|l|}
\hline Medication & Total cost & Cost after reimbursement \\
\hline & & \\
\hline & & \\
\hline & & \\
\hline & & \\
\hline
\end{tabular}

15. What percentage of your antiglaucoma medication costs are reimbursed by the Compulsory Health Insurance Funds?

16. Do you have to take a day off because of outpatient visits?

$\square \quad$ Yes

$\square \quad$ No

$\square \quad$ I do not work 
17. What mean of transport do you use to get to outpatient visits?

$\square \quad$ On foot

$\square \quad$ Public transport/bus

$\square \quad$ Intercity bus

$\square \quad$ Taxi

$\square \quad$ Car

18. Do you need to come with an escort?

$\square \quad$ Yes

$\square \quad$ No (if no, proceed to Question 23)

19. What is your relationship with your escort?

Husband/wife

Family member

Friend

Other:

20. What is the occupation of your escort?

$\begin{array}{ll}\square & \text { Employed } \\ \square & \text { Unemployed } \\ \square & \text { Student } \\ \square & \text { Retired } \\ \square & \text { Other: }- \text {-_-_-_-_-_-_-_-_-_-_-_-_-_- }\end{array}$

21. If the person that accompanies you is employed, does he/she miss work to escort you?

$\square \quad$ Yes

$\square \quad$ No

22. Why do you need an escort to get to outpatient visits?

$\square \quad$ Drives to the hospital

$\square \quad$ Moral support

$\square \quad$ Disability

$\square \quad$ Other:

23. Estimate the cost of one-way transportation per outpatient visit (according to your means of transport):

- $\quad$ Bus ticket price:

- Train ticket price:

- Taxi price:

- $\quad$ Gas price (by car): 
24. How many kilometers do you need to travel to the hospital?

25. How long does it take for you to get to the hospital (hours and minutes)?

26. Do you have any additional costs (hiring a nanny/nurse for family members or other) when you go to outpatient visits?

$\square \quad$ Yes, what expenses:

$\square \quad$ No 